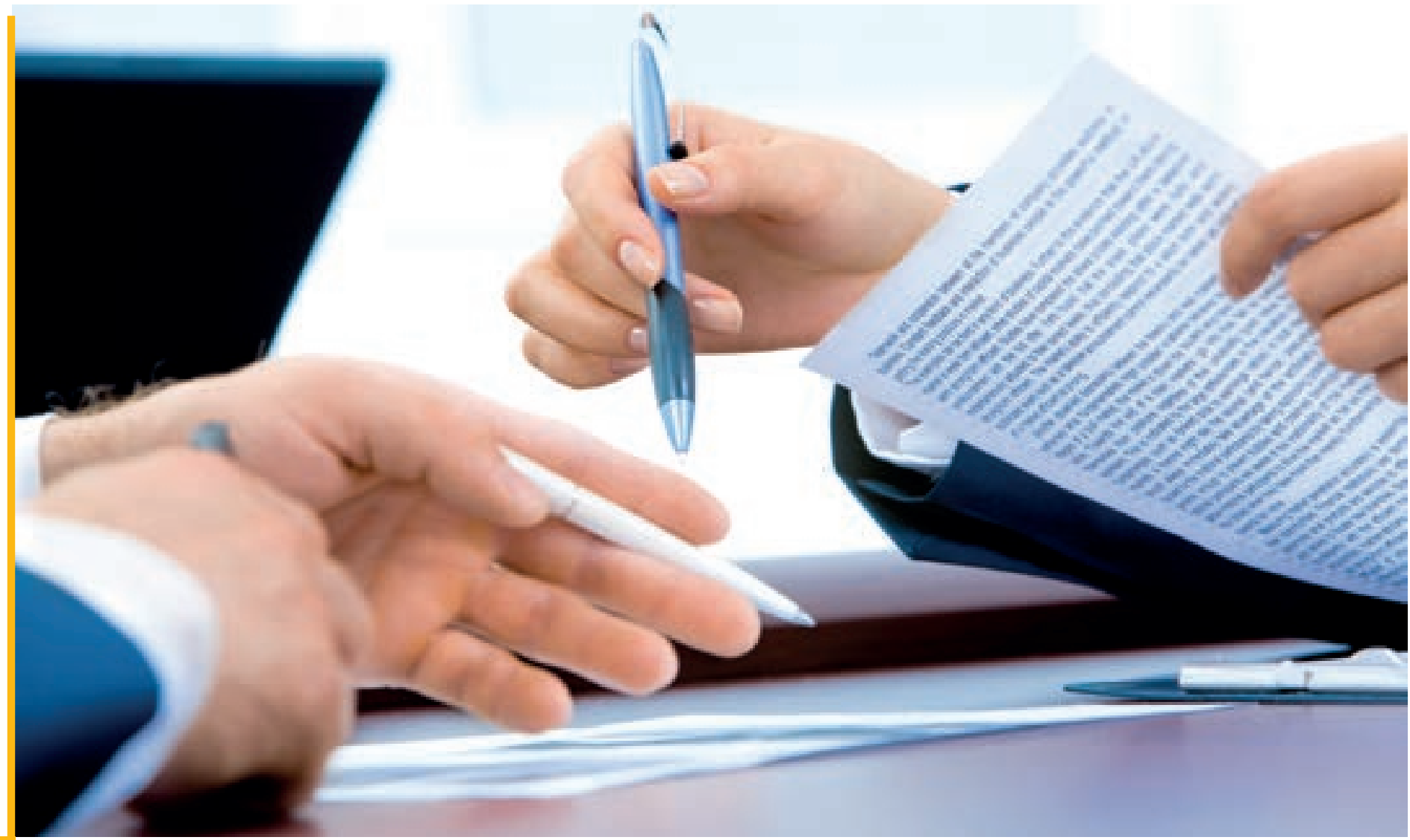

\title{
Los cargos "olvidados" del Sistema de Alta
}

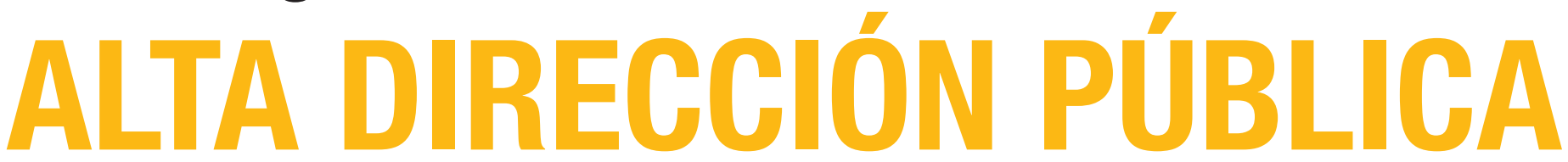

Desde la creación del Sistema de Alta Dirección Pública (SADP) el año 2003, se han ido agregando Servicios con cargos de primer (I) y segundo (II) nivel jerárquico. De esta forma, si en el año 2004 la totalidad de cargos adscritos sumaban 688, el 2018 son 1.162, incluyendo 131 servicios. Siendo 126 cargos de I nivel y 1.043 de II nivel.

Eduardo Abarzúa C. Ph.D. en Ciencias del Trabajo, Universidad Católica de Lovaina, Bélgica. Director Departamento Gestión y Negocios. Edgardo Díaz. M. Ayudante de investigación. Estudiante Ingeniería Comercial, FEN-UAH.

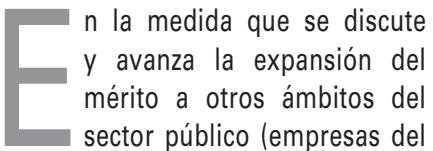
Estado, educación pública, gobierno interior y municipalidades, etc.) parece interesante analizar la situación de los cargos adscritos de II nivel jerárquico. En efecto, sabemos que se trata de 1.043 cargos en 131 servicios. ¿Son muchos, son suficientes, están todos, cuáles fueron los criterios para escoger los que se incluyeron en el SADP?

Teniendo las interrogantes anteriores, como base se buscó información en los decretos leyes respecti-

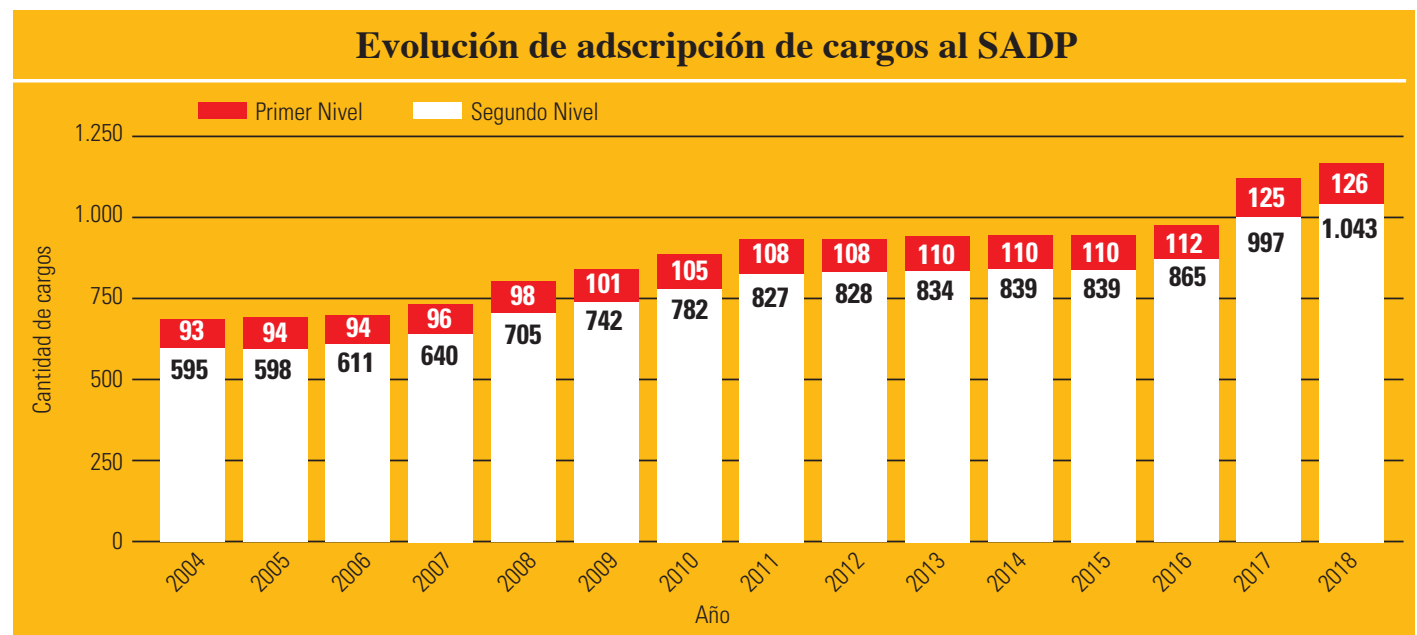

Fuente: Dirección Nacional del Servicio Civil

Observatorio Económico 
Cargos de II nivel adscritos y cargos no incorporados

vos y no aparecen razones del todo unívocas para la adscripción o no de cargos del II nivel al SADP. Por lo mismo, decidimos hacer una pequeña ficción para analizar los organigramas de los servicios adscritos al SADP. Definimos, entonces, que un cargo será de II nivel en la medida que reporte directamente al Jefe Superior del servicio, tenga personas cargo, dirija un proceso clave y administre recursos económicos de la institución. No se trata de criterios antojadizos, sino de aquellos que la teoría de la administración considera para identificar y caracterizar a un directivo.

De los 131 servicios adscritos al SADP, se revisaron 97, dejando a un lado los 29 Servicios de Salud territoriales y otros cinco que corresponden a la nueva institucionalidad de educación pública. Lo anterior basado en el hecho que tienen estructuras únicas en conformación de las autoridades, por lo que serán reservados en un estudio complementario.

El resultado no deja de ser sorprendente. En los 97 servicios considerados, existe un total de 699 cargos de II nivel que son seleccionados por el SADP. Pero si consideramos la estructura de reporte directo al primer nivel aparecen otros 692 cargos adicionales que su provisión quedó fuera del sistema: un $50 \%$ del total de los cargos de segundo nivel.

Si analizamos los tipos de cargos fuera del sistema es posible agruparlos en dos categorías. Por un lado, aparecen una serie de cargos unipersonales como son el de Jefe de gabinete y de Comunicaciones y, otros que, dependiendo del tamaño de la institución, constituyen pequeños equipos cuya función es altamente sensible, se trata de las funciones de Estudio, Jurídica y de Auditoría interna, entre otras. A este grupo de funciones se les puede denominar de apoyo e identificamos 295 cargos, equivalentes al $21 \%$ de los cargos de segundo nivel fuera del sistema'.

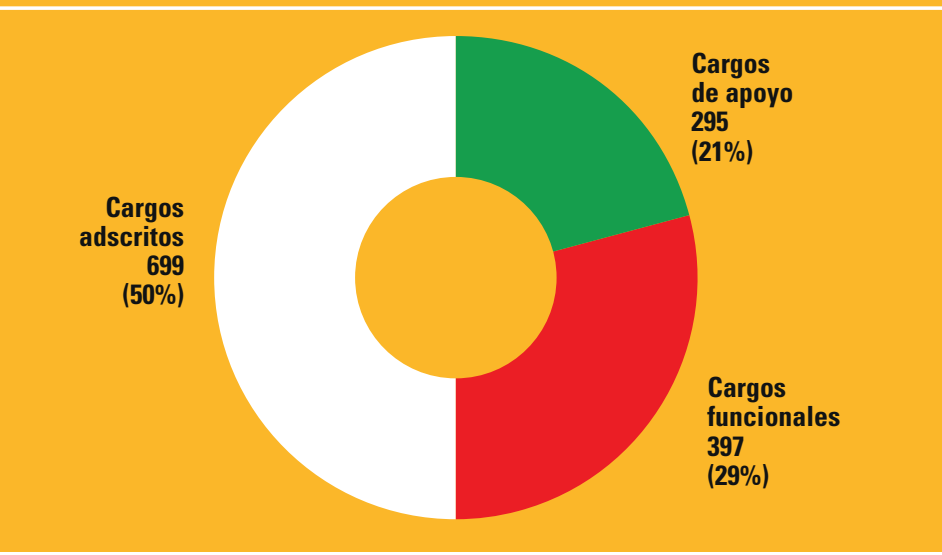

Fuente: Elaboración propia en base a datos oficiales
Por otro lado, aparecen un conjunto de cargos que están estrechamente relacionados con las tareas institucionales como son Encargados/directores regionales, jefaturas especialistas y otras que realizan la gestión interna (Administración y finanzas). A este grupo se les puede denominar funcionales y se identificaron 397 cargos, equivalentes al $29 \%$ de los cargos que hemos denominado fuera del SADP.

Estos datos nos llevan a afirmar que la concursabilidad del II nivel en los Servicios públicos aún no está terminada, quedando por resolver el estatus de un número similar de cargos que hoy no están adscritos al SADP. Lo anterior es un imperativo si se desea fortalecer el sistema. Los equipos directivos cohesionados y empoderados necesitan percibir que sus integrantes están allí pues han cumplido iguales exigencias para integrarlos y han superado los mismos requisitos de selección. Demás está decir que lo anterior se irradia a los demás integrantes de una institución constituyendo las bases de legitimidad del liderazgo directivo y del SADP en general.

La situación ya descrita creemos que puede empeorar ya que la auto ridad tiene la facultad respecto de los cargos de este segundo nivel informal desde la perspectiva del Sistema de Alta Dirección Pública, de dotarlos de "Asignación función crítica", lo que le significa en la práctica una mejora sustancial en sus remuneraciones, cuestión que sabemos también es un elemento de diferenciación positiva y entrega de poder en cualquier organización. Además la autoridad puede entregar esta Asignación a otros profesionales de tercer nivel jerárquico ampliando el tamaño de este segundo nivel informal. Por lo mismo, para complementar, este estudio se solicitó, vía transparencia, la información de cada servicio respecto de las personas y cargos que había recibido dicho complemento en sus rentas en los últimos tres años. Sin embargo a la fecha de cierre de este artículo la información recibida no era suficiente para poblar de manera efectiva a base de datos y extraer conclusiones.

\section{"Al parecer, los servicios públicos siguen teniendo un estatus de deseable desde una buena parte del mundo político, pero no desde una perspectiva profesional como debe suceder en una democracia avanzada"}

Tal vez es hora de observar de manera diferente el fenómeno de profesionalización del Estado, sobre todo en un ámbito tan sensible como es el de los cargos de dirección y que sin duda irradia hacia los otros estamentos, sean profesionales, técnicos, administrativos, auxiliares, fiscalizadores en muchos casos. Conocemos la discusión que cada cuatro años recae sobre el Sistema de Alta Dirección Pública y se han hecho esfuerzos legales relevantes como lo fue la dictación de la ley $N^{\circ} 20.955$, que buscó entre otras cosas reducir la tasa de recambio de los directivos de primer y segundo nivel jerárquico, lo que sin duda es un avance, pero no definitivo a la luz de estos datos que nos muestra la realidad.

Al parecer, los servicios públicos siguen teniendo un estatus de deseable desde una buena parte del mundo político, pero no desde una perspectiva profesional como debe suceder en una democracia avanzada. Recordemos por ejemplo la discusión que se dio a inicios de la nueva administración en 2018 , particularmente política respecto de los Directores Regionales de muchos servicios públicos adscritos al Sistema de Alta Dirección Pública.

El modelo cultural del que somos herederos es relevante de observar en estos procesos de modernización y profesionalización del Estado, que si bien son un importante avance en sí mismos, también están sujetos a resistencias, incluso retrocesos que seguirán afectando el funcionamiento de una administración y la entrega de servicios a la ciudadanía. Aún persiste de modo importante la idea de que si no proveemos los cargos nuevamente, entonces no estamos gobernando con los nuestros, en un mundo de amigos y enemigos, de blancos y negros que no se condice con los avances que ya hemos hecho y que está disponible a nuestros ojos en el mundo desarrollado, a cuyo bienestar aspiramos. $\mathbf{E}$

1. Es importante anotar que en muy pocas instituciones la Función de Gestión de Personas aparece en el segundo nivel jerárquico y adscrita al SADP, lo más probable es que ello la haga vulnerable y de bajo impacto organizacional. 